\title{
Knowledge of pelvic organ prolapse in patients and their information-seeking preferences: comparing Vienna and Moscow
}

\author{
Polina Lyatoshinskaya $^{1}$ - D. Gumina ${ }^{2}$ A. Popov ${ }^{2}$ - M. Koch ${ }^{1,3}$ - M. Hagmann ${ }^{4}$. \\ W. Umek ${ }^{1,3}$
}

Received: 30 December 2015 / Accepted: 23 March 2016 / Published online: 26 April 2016

(C) The Author(s) 2016. This article is published with open access at Springerlink.com

\begin{abstract}
Introduction and hypothesis We hypothesized that knowledge of pelvic organ prolapse (POP) and patient informationseeking preferences are the same in the two capital cities. Methods First-visit patients were recruited at tertiary referral urogynaecological units in Vienna (137) and in Moscow (112). A 16-item scale was used to assess the patient knowledge of POP. The 16 items comprised 12 specific items taken from the Prolapse and Incontinence Knowledge Questionnaire (PIKQ) and four added items. The preliminary psychometric assessment of the knowledge scales in German and Russian was performed in the Vienna and in Moscow centres.

Results The mean total knowledge scores in patients in Vienna and in Moscow were not significantly different: $9.7 \pm 3.5$ vs. $9.8 \pm 2.9(p=0.92)$. Patients in Vienna were more likely to answer questions about the pathogenesis of POP correctly. Patients in Moscow achieved higher scores for items assessing knowledge about the diagnosis of POP. Women in the two study groups equally preferred to obtain information about POP from medical specialists $(72 \%$ and $82 \% ; p=0.61)$, followed by friends and family for patients in Vienna (25\%), and the internet for patients in Moscow (23\%). Patients in
\end{abstract}

Polina Lyatoshinskaya

lyatoshinskaya.polina@yahoo.com

1 Department of Obstetrics and Gynecology, Medical University of Vienna, Waehringer Guertel 18-20, A-1090 Vienna, Austria

2 Pelvic Floor Centre, Moscow Regional Research Institute of Obstetrics and Gynecology, Moscow, Russian Federation

3 Karl-Landsteiner-Institute of Special Gynecology and Obstetrics, Vienna, Austria

4 Department of Statistics, Medical University of Vienna, Vienna, Austria
Vienna were more likely to use printed sources (18\% and $7 \% ; p=0.001)$ than patients in Moscow.

Conclusions The mean level of knowledge of POP did not differ between patients in Vienna and patients in Moscow. The differences between the specific knowledge domains might be explained by different cultural preferences for seeking health information and by the range of the information sources available.

Keywords Information-seeking behaviour $\cdot$ Knowledge of POP · Pelvic organ prolapse $\cdot$ Validation of the questionnaire

\section{Introduction}

Considering worldwide multicultural integration, research on health information-seeking preferences and knowledge of pelvic organ prolapse (POP) in patients of different ethnic backgrounds is of increasing interest [1-7]. Lack of knowledge of pelvic floor disorders can make patients reluctant to seek professional care so that they remain dissatisfied $[8,9]$. Patients may not discuss their problems with a physician because of a lack of understanding and a belief that pelvic floor disorders are a normal consequence of age [10]. Berzuk and Shay found that a low level of knowledge of pelvic floor disorders is associated with a high prevalence of pelvic floor dysfunction, and that health education is associated with an increase in quality of life and a decrease in pelvic floor symptoms [11]. Some authors have suggested that the level of knowledge and patient perception of POP are important predictors of treatmentseeking or nonseeking behaviour [5, 9, 12-14]. The importance of health education among women with POP has been highlighted in many studies $[1,5,8,9,15]$.

The Prolapse and Incontinence Knowledge Questionnaire (PIKQ) for assessing patient knowledge of urinary 
incontinence and POP was designed and validated for Englishspeaking patients by Sha et al. [16]. This questionnaire has been used to evaluate knowledge of POP in some US and Canadian English-speaking populations [1, 5, 9, 11, 17]. A literature search yielded no studies providing information about knowledge of POP among German-speaking and Russianspeaking populations, and there are no validated versions of the PIKQ in the German and Russian languages. Extension of the research on this issue in Russia-speaking and Germanspeaking countries could help avoid patient misconceptions about POP in multilingual populations and help standardize the evaluation of POP knowledge in a multicultural milieu.

The aim of this study was to evaluate the level of knowledge of POP and analyse health information-seeking preferences in patients presenting at tertiary referral centres in Vienna and in Moscow. The null hypothesis was that knowledge of POP and patient information-seeking preferences are the same in Vienna and Moscow.

\section{Materials and Methods}

\section{Patients and Institutions}

The ethics committees of both study centres approved the study (IRB 1225/2014 and 9/2014). Patients were recruited from two dedicated urogynaecology outpatient clinics of academic tertiary referral centres in Vienna and Moscow (Medical University of Vienna and Pelvic Floor Center at the Regional Research Institute of Obstetrics and Gynaecology Moscow). At both institutions 100-150 surgical POP repairs are performed per year and the POP-Q system is used in all patients. All patients presenting for their initial visit with the referral diagnosis POP were asked to participate and were handed the questionnaires after consenting to participate, but before consultation with the examining physician. The referral diagnosis of POP was confirmed by pelvic examination. Healthcare workers and patients with professional medical background as well as patients lacking language skills were excluded from the study.

\section{Questionnaire}

The study questionnaire included information on demography, level of education, annual household income, duration of symptoms, symptom severity, previous experience with POP and sexual activity. A four-point scoring system was used to assess the severity of the symptoms (Pelvic Floor Questionnaire [18]). The sources of information about POP used by patients prior to the first visit to the tertiary referral POP centres were studied according to the procedure described by Pakbaz et al. [14] and were available in both cities. Patients were asked whether they preferred seeking information through printed sources, internet, broadcast media or family, friends and healthcare providers.

The patients' desire for information was estimated using two items assessed using a five-point Likert scale. One item reflected how strongly the patient felt about wanting to be informed before making a shared decision about treatment. The second item evaluated the patient's need for additional information associated with trust in the physician (Table 1).

\section{Structure of the knowledge of POP scale}

A 17-item scale was used to assess patient knowledge of POP (Table 2). Twelve items assessing knowledge of pathogenesis, diagnosis and treatment of POP were taken from the PIKQ [16]. Five items were added to determine the patient knowledge of pathoanatomy, aetiology of the disease and treatment. Patients were also asked about surgical approaches, the use of mesh, and the option of uterus-preservation.

The entire questionnaire was translated into German and Russian and re-translated into English. It was tested in 20 healthy women without any symptoms of POP to determine whether the questions were understandable and the language was appropriate.

The psychometric assessment of knowledge scales included analysis of reliability with internal consistency using the Cronbach's alpha coefficient of each scale. A confirmatory factor analysis (CFA) was performed to evaluate the constructed validity of each scale. Absolute fit indices from the chisquared statistic, indices from the parsimony class including the root mean square error of approximation, and comparative fit characteristics including the comparative fit index and nonnormed fit index [19] were calculated. Ordinal logistic regression was applied to identify the contribution of demographic and clinical variables and information-seeking preferences to the knowledge score. Statistical analysis was carried out using software statistical environment $\mathrm{R}$ i386 version 3.1.2 (The $\mathrm{R}$ Foundation for Statistical Computing).

\section{Results}

The questionnaire was administered to 137 POP patients in Vienna and to 112 POP patients in Moscow. Of these patients, 13 in Vienna and 7 in Moscow were excluded after completing the questionnaire because of a medical background (doctors, nurses and other healthcare providers). Six patients in Vienna were excluded because of insufficient German language skill. The plausibility-analysis yielded eight questionnaires in Vienna and ten questionnaires in Moscow with implausible answers. These questionnaires were also excluded from further analysis. Patient demographics are presented in Table 3. Patients in Moscow were more likely to have a higher level of education and lower parity than patients in Vienna. 
Table 1 Five-point Likert scales for evaluating informationseeking preferences
I. I need the information about the disease before my visit to the physician to feel free choosing the best treatment
1. strongly disagree
2. disagree
3. neither agree or disagree
4. agree
5. strongly agree

II. I do not need to be informed about the disease; I trust my physician to make the treatment decision
1. strongly disagree
2. disagree
3. neither agree or disagree
4. agree
5. strongly agree

Table 2 POP knowledge questionnaire

\begin{tabular}{|c|c|c|}
\hline Item & Domain & Questions \\
\hline \multicolumn{3}{|c|}{ Items from the PIKQ Pelvic Organ Prolapse Scale } \\
\hline 1 & Pathogenesis & $\begin{array}{l}\text { Pelvic organ prolapse is more common in young women than in old woman. } \\
\text { agree disagree don't know }\end{array}$ \\
\hline 2 & Pathogenesis & $\begin{array}{l}\text { Giving birth many times may lead to pelvic organ prolapse. } \\
\text { agree } \quad \text { disagree don't know }\end{array}$ \\
\hline 3 & Pathogenesis & $\begin{array}{l}\text { Pelvic organ prolapse can happen at any age. } \\
\text { agree } \quad \text { disagree }\end{array}$ \\
\hline 4 & Treatment & $\begin{array}{l}\text { Certain exercises can help to stop pelvic organ prolapse from getting worse. } \\
\begin{array}{lll}\text { agree } & \text { disagree } & \text { don't know }\end{array}\end{array}$ \\
\hline 5 & Diagnosis & $\begin{array}{l}\text { Symptoms of pelvic organ prolapse may include heaviness and/or pressure. } \\
\text { agree } \\
\text { disagree }\end{array}$ \\
\hline 6 & Diagnosis & $\begin{array}{l}\text { A good way for a doctor to diagnose pelvic organ prolapse is by examining the patient. } \\
\text { agree } \quad \text { disagree don't know }\end{array}$ \\
\hline 7 & Treatment & $\begin{array}{l}\text { Once a patient has pelvic organ prolapse, not much can be done to help her } \\
\text { agree } \quad \text { disagree don't know }\end{array}$ \\
\hline 8 & Pathogenesis & $\begin{array}{l}\text { Heavy lifting on a daily basis can lead to pelvic organ prolapse. } \\
\text { agree } \quad \text { disagree }\end{array}$ \\
\hline 9 & Treatment & $\begin{array}{l}\text { Surgery is possible treatment for pelvic organ prolapse. } \\
\text { agree } \quad \text { disagree don't know }\end{array}$ \\
\hline 10 & Diagnosis & $\begin{array}{l}\text { Doctors can run a blood test to diagnose pelvic organ prolapse. } \\
\text { agree } \quad \text { disagree don't know }\end{array}$ \\
\hline 11 & Treatment & $\begin{array}{l}\text { A rubber ring called a pessary can be used to treat symptoms of pelvic organ prolapse } \\
\text { agree } \quad \text { disagree don't know }\end{array}$ \\
\hline 12 & Pathogenesis & $\begin{array}{l}\text { People who are obese are likely to get pelvic organ prolapse. } \\
\text { agree } \quad \text { disagree don't know }\end{array}$ \\
\hline \multicolumn{3}{|c|}{ Additional items in German and Russian versions of the scale } \\
\hline 13 & Pathogenesis & $\begin{array}{l}\text { Infections of the urogenital tract can cause pelvic organ prolapse. } \\
\text { agree } \quad \text { disagree }\end{array}$ \\
\hline 14 & Diagnosis & $\begin{array}{l}\text { Pelvic organ prolapse is the bulging of the uterus, vagina, bladder or rectum. } \\
\text { agree } \\
\text { disagree don't know }\end{array}$ \\
\hline \multirow[t]{2}{*}{15} & Treatment & $\begin{array}{l}\text { The surgical correction of pelvic organ prolapse can be done using a vaginal or } \\
\text { abdominal method. }\end{array}$ \\
\hline & & don't know \\
\hline 16 & Treatment & $\begin{array}{l}\text { The removal of the uterus is the only possible correction of pelvic organ prolapse. } \\
\text { agree disagree don't know }\end{array}$ \\
\hline 17 & Treatment & $\begin{array}{l}\text { Mesh implants are used to correct pelvic organ prolapse. } \\
\text { agree disagree don't know }\end{array}$ \\
\hline
\end{tabular}


Table 3 Demographic characteristics and POP history in each patient group

\begin{tabular}{|c|c|c|c|}
\hline Characteristic & Vienna $(n=110)$ & Moscow $(n=95)$ & $p$ value \\
\hline Age (years), mean $\pm \mathrm{SD}$ & $59.7 \pm 13.1$ & $61.4 \pm 9.0$ & 0.27 \\
\hline \multicolumn{4}{|l|}{ Marital status, $\%$} \\
\hline Married & 56 & 60 & 0.82 \\
\hline Single & 6 & 1 & 0.19 \\
\hline Divorced & 25 & 11 & 0.04 \\
\hline Widowed & 15 & 28 & 0.07 \\
\hline \multicolumn{4}{|l|}{ Highest level of education, $\%$} \\
\hline Secondary school & 56 & 19 & 0.001 \\
\hline Undergraduate & 29 & 26 & 0.99 \\
\hline Graduate school & 15 & 55 & 0.001 \\
\hline \multicolumn{4}{|l|}{ Menopausal status, $\%$} \\
\hline Premenopausal & 25 & 14 & 0.15 \\
\hline Postmenopausal & 74 & 86 & 0.19 \\
\hline Parity, mean $\pm \mathrm{SD}$ & $2.2 \pm 1.1$ & $1.7 \pm 0.7$ & 0.001 \\
\hline POP symptom severity score, mean \pm SD & $2.2 \pm 0.9$ & $2.2 \pm 0.8$ & 0.53 \\
\hline POP symptom duration (years), mean $\pm \mathrm{SD}$ & $7.5 \pm 8.5$ & $10.2 \pm 9.4$ & 0.04 \\
\hline Sexually active, $\%$ & 39 & 23 & 0.10 \\
\hline Sexually inactive because of POP, $\%$ & 22 & 27 & 0.99 \\
\hline \multicolumn{4}{|c|}{ Previous doctor visits because of POP symptoms, $\%$} \\
\hline None & 20 & 18 & 0.89 \\
\hline One & 44 & 38 & 0.99 \\
\hline Two or more & 36 & 44 & 0.24 \\
\hline \multicolumn{4}{|l|}{ Previous POP treatment, $\%$} \\
\hline Conservative & 41 & 28 & 0.43 \\
\hline Surgery & 23 & 16 & 0.66 \\
\hline \multicolumn{4}{|l|}{ Mean household income (euros), $\%^{\mathrm{a}}$} \\
\hline$<20,000$ & 68 & 73 & 0.47 \\
\hline $20,000-40,000$ & 20 & 13 & 0.26 \\
\hline $40,000-60,000$ & 3 & 2 & 0.99 \\
\hline$>60,000$ & 3 & 1 & 0.73 \\
\hline
\end{tabular}

${ }^{\text {a }}$ Response rates $86 \%$ in Vienna and $73 \%$ in Moscow

\section{Validation of the knowledge scale}

Psychometric assessment of the POP knowledge scale in German was performed on 110 questionnaires from the Vienna centre and of the knowledge scale in Russian on 95 questionnaires from the Moscow centre. The results of the CFA suggested a good fit of the 17-item knowledge scale in German (chi-squared $=138.921$ ) and a poor fit of the knowledge scale in Russian (chisquared $=153.072$; Table 4). Removal of item 13 from both the German and Russian knowledge scales improved the model fit and reliability of both scales (Table 5).Cronbach's alpha coefficients for the modified German and Russian scales $(0.782$ and 0.667 , respectively) confirmed acceptable internal consistency of both scales.

\section{Analysis of the knowledge scales}

The mean total knowledge scores (16-item scale) did not show statistically significant differences between the patient groups (9.7 \pm 3.5 for patients in Vienna, and $9.8 \pm 2.9$ for patients Moscow; $p>0.05$; Table 6).

However, analysing the different domains of the scale separately, patients in Vienna were achieved higher scores for questions in the pathogenesis domain than patients in Moscow (mean scores $2.9 \pm 1.5$ vs. $2.6 \pm 1.2 ; p=0.05$ ); and patients in Moscow achieved higher scores for questions in the diagnostic domain than patients in Vienna $(2.6 \pm 0.9$ vs. $3.0 \pm 1.0 ; p<0.05$ ). Patients in Vienna were less well informed about the use of mesh in prolapse surgery than patients in Moscow (32\% vs. $80 \%$ correct answers; $p<0.001$; Table 2 , item 17). There was no significant difference between the 
Table 4 Confirmatory factor analysis of the POP knowledge scales with the model fit indices

\begin{tabular}{|c|c|c|c|c|}
\hline & \multicolumn{2}{|c|}{ German scale } & \multicolumn{2}{|c|}{ Russian scale } \\
\hline & 17 items & 16 items & 17 items & 16 items \\
\hline Chi-squared $^{\mathrm{a}}$ & 138.921 & 121.156 & 153.072 & 127.554 \\
\hline$p$ scaled $^{\mathrm{b}}$ & 0.102 & 0.120 & 0.019 & 0.058 \\
\hline Comparative fit index & 0.951 & 0.952 & 0.711 & 0.793 \\
\hline Non-normed fit index & 0.944 & 0.945 & 0.670 & 0.761 \\
\hline Root mean square error of approximation & 0.038 & 0.038 & 0.052 & 0.047 \\
\hline
\end{tabular}

${ }^{a}$ Values closer to zero indicate a better fit

${ }^{\mathrm{b}}$ Values greater than 0.05 indicate a good fit mean scores for questions in the therapy domain between patients in Vienna and patients in Moscow (4.1 \pm 1.9 vs. 4.2 $\pm 1.7 ; p>0.05)$.

\section{Information-seeking preferences and sources of information}

Analysing preferences for health information seeking, patients in Vienna were less likely to need information about their condition before the clinical visit than patients in Moscow (five-point Likert scale mean scores: $2.9 \pm 1.2$ vs. $3.8 \pm 1.3$; $p<0.001$ ). There was no difference between the patient groups in non-seeking behaviour associated with trust in the physician (five-point Likert scale mean scores: $3.7 \pm 1.3$ vs. $3.8 \pm 1.2 ; p>0.05)$.

Analysing patient preferences for sources of information, most patients in both study-groups preferred information about POP from medical specialists ( $72 \%$ and $82 \%$, respectively; $p>0.05$ ), followed by friends and family for patients in Vienna (25\%), and the internet for patients in Moscow (23\%; Fig. 1). Of the patients in Vienna and Moscow, $21 \%$ and $14 \%$, respectively, were informed about POP by their general practitioner $(p>0.05)$. Patients in Vienna were more likely to use printed sources than patients in Moscow (18\% and $7 \%$, respectively; $p<0.05$ ). Radio and television did not provide enough information in either country $(6 \%$ and $6 \%$ respectively; $p>0.05$ ).
Table 5 Latent variable confirmatory factor analysis of the knowledge scales

\begin{tabular}{|c|c|c|c|c|c|c|}
\hline \multirow{2}{*}{$\begin{array}{l}\text { Item } \\
\text { no. }\end{array}$} & \multicolumn{3}{|c|}{ German scale $(n=110)$} & \multicolumn{3}{|c|}{ Russian scale $(n=95)$} \\
\hline & $\begin{array}{l}\text { Standardized } \\
\text { coefficient }\end{array}$ & $\begin{array}{l}\text { Standard } \\
\text { error }\end{array}$ & $p$ value & $\begin{array}{l}\text { Standardized } \\
\text { coefficient }\end{array}$ & $\begin{array}{l}\text { Standard } \\
\text { error }\end{array}$ & $p$ value \\
\hline 1 & 0.786 & 0.069 & $<0.0001$ & 0.420 & 0.118 & 0.0004 \\
\hline 2 & 0.599 & 0.108 & $<0.0001$ & 0.444 & 0.117 & 0.0002 \\
\hline 3 & 0.501 & 0.106 & $<0.0001$ & 0.436 & 0.115 & 0.0002 \\
\hline 4 & 0.595 & 0.106 & $<0.0001$ & 0.534 & 0.109 & $<0.0001$ \\
\hline 5 & 0.337 & 0.117 & 0.0039 & 0.266 & 0.143 & 0.0630 \\
\hline 6 & 0.256 & 0.149 & 0.0853 & 0.648 & 0.153 & $<0.0001$ \\
\hline 7 & 0.616 & 0.100 & $<0.0001$ & 0.411 & 0.118 & 0.0005 \\
\hline 8 & 0.422 & 0.131 & 0.0013 & 0.565 & 0.209 & 0.0068 \\
\hline 9 & 0.420 & 0.117 & 0.0003 & 0.697 & 0.144 & $<0.0001$ \\
\hline 10 & 0.733 & 0.084 & $<0.0001$ & 0.480 & 0.112 & $<0.0001$ \\
\hline 11 & 0.304 & 0.120 & 0.0110 & 0.352 & 0.128 & 0.0059 \\
\hline 12 & 0.776 & 0.079 & $<0.0001$ & 0.419 & 0.127 & 0.0009 \\
\hline 13 & 0.649 & 0.091 & $<0.0001$ & 0.018 & 0.132 & 0.8902 \\
\hline 14 & 0.505 & 0.115 & $<0.0001$ & 0.750 & 0.121 & $<0.0001$ \\
\hline 15 & 0.446 & 0.107 & $<0.0001$ & 0.441 & 0.124 & 0.0004 \\
\hline 16 & 0.775 & 0.081 & $<0.0001$ & 0.481 & 0.134 & 0.0003 \\
\hline 17 & 0.541 & 0.110 & $<0.0001$ & 0.302 & 0.155 & 0.0512 \\
\hline
\end{tabular}


Table 6 Modified 16-item POP knowledge scores in patients in Vienna and in Moscow

\begin{tabular}{llll}
\hline \multirow{2}{*}{ Domain } & \multicolumn{2}{l}{ Knowledge score } \\
\cline { 2 - 4 } & Range & Vienna (mean \pm SD) & Moscow (mean \pm SD) \\
\hline Pathogenesis & $0-5$ & $2.9 \pm 1.5^{*}$ & $2.6 \pm 1.2$ \\
Diagnostic & $0-4$ & $2.6 \pm 0.9$ & $3.0 \pm 1.0^{*}$ \\
Therapy & $0-7$ & $4.1 \pm 1.9$ & $4.2 \pm 1.7$ \\
Total scale & $0-16$ & $9.7 \pm 3.5$ & $9.8 \pm 2.9$ \\
\hline
\end{tabular}

$* p \leq 0.05$

\section{Predictive factors for level of knowledge}

The internet and printed material as additional sources of information were the most important predictors of more knowledge of POP in both groups (Table 7).

A higher information-seeking preference score was a significant predictor of a higher knowledge score in patients in Vienna, and a lower trust in physician score was a significant predictor of a higher knowledge score in patients in Vienna and patients in Moscow (OR 0.69, $95 \%$ CI 0.52-0.89, and OR $0.7,95 \%$ CI $0.51-0.9$, respectively). Additional predictors of the knowledge score in patients in Moscow were a low level of education (OR 0.29, $95 \%$ CI $0.1-0.77$ ) and a sexually active patient (OR 2.65; $95 \%$ CI 1.1-6.49).

\section{Discussion}

This study focused on the evaluation of patient knowledge of POP at tertiary prolapse centres in Vienna and Moscow, and confirmed the hypothesis that levels of knowledge of POP do not differ between these two cities. To evaluate patient knowledge of POP in German and Russian populations we developed validated and reliable extended versions of the POP
Knowledge Scale in the German and Russian languages. Translation and psychometric adaptation of reliable questionnaires for patients speaking different languages allows research to be extended in other countries [7, 18, 20-22].

We did not find any significant difference in the mean total knowledge score in women with POP between Vienna and Moscow (9.7 vs. 9.8). Sha et al. found a mean knowledge score of 8.2 using the original 12-item POP scale [16]. These authors also recruited patients presenting at tertiary care POP centre. Lower average PIKQ scores were found by Mandimika et al. [9] in English-speaking community-dwelling women (5.5) and by Dunivan et al. [1] in elder American Indian women (5.4). The percentile rank should be calculated to compare the mean scores of 16-item and 12-item POP knowledge scales.

The analysis comparing knowledge domains did not reveal any significant differences between the mean scores of the patients in Vienna and Moscow. However, the detailed analysis of the therapy items revealed that the patients in Moscow were more informed about the use of mesh for prolapse correction than patients in Vienna (80\% vs. $32 \%$ correct answers). This may be explained by the fact that mesh implants are more commonly used in Russia to correct prolapse [23], in contrast to the current practice in Austria [24]. In a study of patient knowledge of vaginal mesh surgery, Brown et al. found that nearly two thirds of patients presenting at a tertiary referral centre in Michigan had received information about this issue from medical professionals or from the television [25].

Level of knowledge is an integrative parameter that may depend on numerous social and demographic variables. One of the most important predictive factors is the patient's wish to be informed. It has been suggested that not all patients want to be involved in medical decision making and that unnecessarily detailed information can induce emotional stress in passively inclined patients [26]. Sung et al. investigated information-seeking preferences in women with pelvic floor
Fig. 1 Patients' sources of information about pelvic organ prolapse

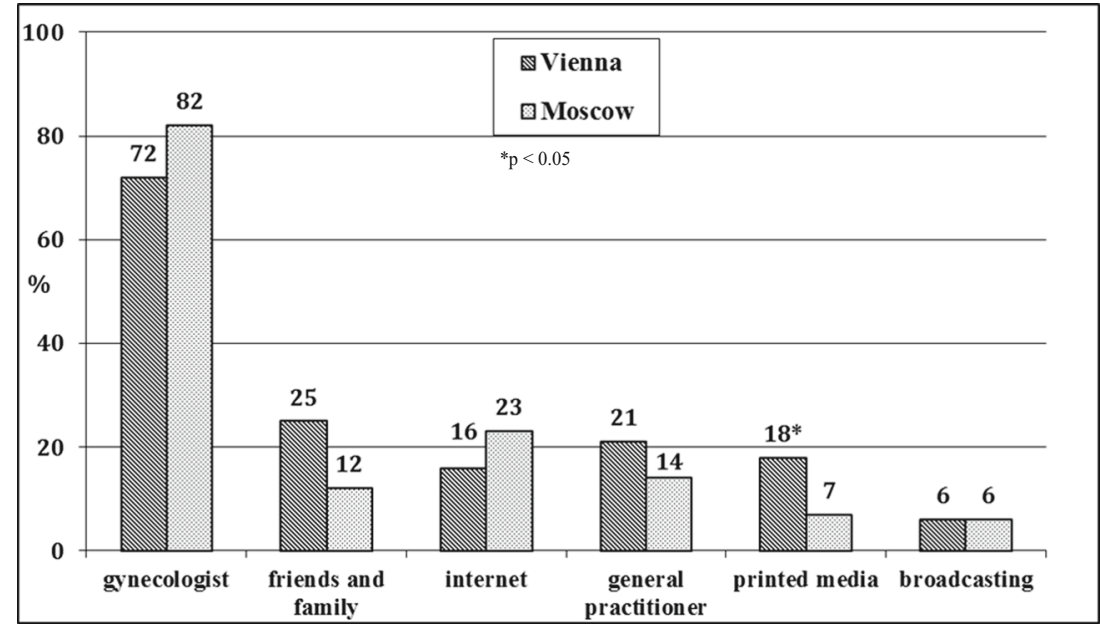


Table 7 Predictive factors for higher levels of knowledge

\begin{tabular}{|c|c|c|c|c|}
\hline \multirow[t]{2}{*}{ Factor } & \multicolumn{2}{|c|}{ Vienna centre $(n=110)$} & \multicolumn{2}{|c|}{ Moscow centre $(n=95)$} \\
\hline & Odds ratio & $\begin{array}{l}95 \% \text { confidence } \\
\text { interval }\end{array}$ & Odds ratio & $\begin{array}{l}95 \% \text { confidence } \\
\text { interval }\end{array}$ \\
\hline Age & 0.99 & $0.96-1.01$ & 0.99 & $0.95-1.03$ \\
\hline Marital status & 0.49 & $0.17-1.35$ & 0.74 & $0.32-1.71$ \\
\hline \multicolumn{5}{|l|}{ Level of education } \\
\hline Secondary school & 0.55 & $0.27-1.09$ & 0.29 & $0.10-0.77$ \\
\hline Undergraduate & 2.00 & $0.95-4.29$ & 1.23 & $0.52-2.89$ \\
\hline Graduate school & 1.10 & $0.40-4.05$ & 1.78 & $0.85-3.78$ \\
\hline Menopausal status & 1.19 & $0.54-2.68$ & 1.25 & $0.44-3.49$ \\
\hline Parity & 0.85 & $0.62-1.17$ & 1.08 & $0.62-1.89$ \\
\hline Sexually active/inactive & 1.83 & $0.92-3.67$ & 2.65 & $1.10-6.49$ \\
\hline Severity of POP symptoms & 1.24 & $0.86-1.80$ & 0.88 & $0.56-1.38$ \\
\hline Previous consulting visits & 1.39 & $0.89-2.21$ & 1.01 & $0.63-1.64$ \\
\hline Previous POP treatment & 1.44 & $0.73-2.86$ & 1.44 & $0.69-3.03$ \\
\hline Duration of POP symptoms & 1.01 & $0.96-1.05$ & 0.98 & $0.95-1.02$ \\
\hline Household income & 1.62 & $0.95-2.83$ & 1.49 & $0.77-2.98$ \\
\hline Stronger information-seeking preferences & 1.36 & $1.03-1.82$ & 1.08 & $0.80-1.46$ \\
\hline Patient's trust in physician & 0.69 & $0.52-0.89$ & 0.70 & $0.51-0.90$ \\
\hline \multicolumn{5}{|l|}{ Sources of information about POP } \\
\hline Family and friends & 2.31 & $1.07-5.07$ & 1.59 & $0.48-5.43$ \\
\hline General practitioner & 1.25 & $0.57-2.76$ & 0.21 & $0.06-0.65$ \\
\hline Gynaecologist & 1.72 & $0.79-3.78$ & 2.89 & $1.07-8.28$ \\
\hline Newspapers and magazines & 4.25 & $1.69-11.18$ & 6.56 & $3.05-24.44$ \\
\hline Radio and television & 4.05 & $0.92-21.31$ & 1.42 & $0.28-7.32$ \\
\hline Internet & 4.67 & $1.77-11.42$ & 5.12 & $2.06-13.26$ \\
\hline
\end{tabular}

Odds ratios and $95 \%$ confidence intervals were extracted from the ordinal logistic regression model

If the confidence interval contains the relative risk of 1.00 , the factor is not significantly predictive of the knowledge score; if the confidence interval is less than 1.00 , the factor is significantly predictive of a decreases in score, and if more than 1.00 is significantly predictive of an increase in the score disorders using the Autonomy Preference Index (API) [27]. Given that there were no validated versions of this scale in either German or Russian, we tried to formulate our questions taking into consideration the cultural particularities of the doctor-patient relationships and trust in physicians in the two countries. The patients in Moscow showed significantly stronger information-seeking preferences prior to the clinical visit in contrast to patients in Vienna. This may be explained by differences between the "models" of doctor-patient relationships between the two populations [28]. While an "informative" model of the doctor-patient relationship is more popular in German-speaking areas, a more "paternalistic" character of the interaction predominates in Russian culture historically.

The higher level of knowledge of POP was associated with stronger preferences for information seeking in patients in Vienna, but not with greater trust in the physician. In contrast, the trust in physician predicted the lower scores of the knowledge scale in patients in both Vienna and Moscow. Similar findings have not been reported previously. In contrast to the findings of Mandimika et al. [9], we could not find any association between knowledge scores and parameters including age, parity and household income in both groups. It is possible that there was some inaccuracy in the income analysis due to the low income variability and the poor response rate to this item in this study. This is similar to the finding of Pakbaz et al. [14] who found that POP patients in Vienna and Moscow prefer to obtain their information from specialized health providers. Given that the women rated the physician's opinion as one of the most important factors in making a decision, physicians should avoid the authoritative form of the patient-physician interaction and provide the patient with all relevant information to make a shared decision about therapy. We believe that providing more information about new diagnostic tools and prolapse therapeutic procedures in press media sources or via the Internet could significantly improve the understanding of POP in patients in Vienna and Moscow.

In summary, our findings did not suggest global knowledge gaps in patients with prolapse in Vienna and Moscow. The 
differences in specific knowledge might be explained by the different cultural preferences for seeking health information and by the range of information sources available. The authors would like to encourage further research in both populations to investigate more fully the sociocultural reasons for patients' misconceptions about POP.

Acknowledgments Open access funding provided by Medical University of Vienna. We are grateful to Prof. Paul Riss for his guidance in the planning of this project and his review of the manuscript.

\section{Compliance with ethical standards}

Conflicts of interest W. Umek: European Speciality Pharma, Pfizer, Astellas, speaker's fee.

All other authors report no conflicts of interest.

Open Access This article is distributed under the terms of the Creative Commons Attribution 4.0 International License (http:// creativecommons.org/licenses/by/4.0/), which permits unrestricted use, distribution, and reproduction in any medium, provided you give appropriate credit to the original author(s) and the source, provide a link to the Creative Commons license, and indicate if changes were made.

\section{References}

1. Dunivan GC, Komesu YM, Cichowski SB et al (2015) Elder American Indian women's knowledge of pelvic floor disorders and barriers to seeking care. Female Pelvic Med Reconstr Surg 21(1):34-38

2. Good MM, Korbly N, Kassis NC et al (2013) Prolapse-related knowledge and attitude toward the uterus in women with pelvic organ prolapse symptoms. Am J Obstet Gynecol 209:481.e1-481.e6

3. Hatchett L, Hebert-Beirne J, Tenfelde S et al (2011) Knowledge and perceptions of pelvic floor disorders among African American and Latina women. Female Pelvic Med Reconstr Surg 17(4):190-194

4. Khan AA, Sevilla K, Wieslander CK et al (2013) Communication barriers among Spanish-speaking women with pelvic floor disorders: lost in translation? Female Pelvic Med Reconstr Surg 19(3): 157-164. doi:10.1097/SPV.0b013e318288ac1c

5. Mandimika CL, Murk W, McPencow AM et al (2014) Knowledge of pelvic floor disorders in a population of community-dwelling women. Am J Obstet Gynecol 210(2):165.e1-165.e9

6. Rizk DE (2008) Ethnic differences in women's knowledge level and other barriers to care seeking and the true incidence and/or prevalence rate of female pelvic floor disorders. Int Urogynecol $\mathrm{J}$ Pelvic Floor Dysfunct 19(11):1587-1588

7. Utomo E, Korfage IJ, Wildhagen MF et al (2015) Validation of the Urogenital Distress Inventory (UDI-6) and Incontinence Impact Questionnaire (IIQ-7) in a Dutch population. Neurourol Urodyn 34(1):24-31

8. Kiyosaki K, Ackerman LA, Histed S et al (2012) Patient understanding of pelvic floor disorders: what women want to know. Female Pelvic Med Reconstr Surg 18(3):137-142

9. Mandimika CL, Murk W, McPencow AM et al (2015) Racial disparities of pelvic floor disorders among community-dwelling women. Female Pelvic Med Reconstr Surg 21(5):287-292

10. Wieslander CK, Alas A, Dunivan GC et al (2015) Misconceptions and miscommunication among Spanish-speaking and English- speaking women with pelvic organ prolapse. Int Urogynecol $\mathrm{J}$ 26(4):597-604

11. Berzuk K, Shay B (2015) Effect of increasing awareness of pelvic floor muscle function on pelvic floor dysfunction: a randomized controlled trial. Int Urogynecol J 26(6):837-844

12. Krause HG, Natukunda H, Singasi I et al (2014) Treatment-seeking behaviour and social status of women with pelvic organ prolapse, 4th-degree obstetric tears, and obstetric fistula in western Uganda. Int Urogynecol J 25(11):1555-9

13. Morill M, Lukacz E, Lawrence J et al (2007) Seeking healthcare for pelvic floor disorders: a population-based study. Am J Obstet Gynecol 197:86.e1-86.e6

14. Pakbaz M, Rolfsman E, Mogren I et al (2011) Vaginal prolapse perception and health-seeking behaviour among women prior to gynecological surgery. Acta Obstet Gynecol Scand 90:1115-1120

15. Gomman HM, Nossier SA, Fotohi EM et al (2001) Prevalence and factors associated with genital prolapse: a hospital-based study in Alexandria (Part I). J Egypt Public Health Assoc 76(5-6):313-335

16. Sha AD, Massagli MP, Kohli N et al (2008) A reliable, valid instrument to assess patient knowledge about urinary incontinence and pelvic organ prolapse. Int Urogynecol J 19:1283-1289

17. Geoffrion R, Robert M, Ross S et al (2009) Evaluating patient learning after an educational program for women with incontinence and pelvic organ prolapse. Int Urogynecol J Pelvic Floor Dysfunct 20(10):1243-1252

18. Baessler K, O'Neill SM, Maher CF et al (2010) A validated self-administered female pelvic floor questionnaire. Int Urogynecol J 21:163-172

19. Schreiber JB, Nora A, Stage FK et al (2010) Reporting structural equation modelling and confirmatory factor analysis results: a review. J Educ Res 99(6):323-338

20. Cam C, Sakalli M, Ay P et al (2007) Validation of the short forms of the incontinence impact questionnaire (IIQ-7) and the urogenital distress inventory (UDI-6) in a Turkish population. Neurourol Urodyn 26(1):129-133

21. Cam C, Sancak P, Karahan N et al (2009) Validation of the short form of the pelvic organ prolapse urinary incontinence sexual questionnaire (PISQ-12) in a Turkish population. Eur J Obstet Gynecol Reprod Biol 146(1):104-107

22. Pushkar DY, Gvozdev MY, Tupikina NV (2013) Questionnaires as a tool for assessing the quality of life in urogynecological patients. Rossiysky Vestn Akushera-Ginekologa 1:23-29, http://www. mediasphera.ru/journals/akuvest/974/eng/15699/

23. Krasnopolskaya IW, Popov AA, Tyurina AA et al (2014) Analysis of vaginal sacrospinous fixation versus laparoscopic sacrocolpopexy used in the treatment of patient with genital prolapse. Rossiysky Vestn Akushera-Ginekologa 5:66-70, http://www. mediasphera.ru/journals/akuvest/1224/eng/19978/

24. Bjelic-Radisic V, Aigmueller T, Preyer O et al (2014) Vaginal prolapse surgery with transvaginal mesh: results of the Austrian registry. Int Urogynecol J 25(8):1047-1052. doi:10.1007/s00192-014-2333-X

25. Brown LK, Fenner DE, Berger MB et al (2013) Defining patients knowledge and perceptions of vaginal mesh surgery. Female Pelvic Med Reconstr Surg 19(5):282-287

26. Kiesler DJ, Auerbach SM (2006) Optimal matches of patient preferences for information, decision-making and interpersonal behaviour: evidence, models and intervention. Patient Educ Couns 61:319-341

27. Sung VW, Raker CA, Myers DL et al (2010) Treatment decisionmaking and information-seeking preferences in women with pelvic floor disorders. Int Urogynecol J 21(9):1071-1078

28. Emanuel EJ, Emanuel LL (1992) Four models of the physicianpatient relationship. JAMA 267(16):2221-2226 